regularly every four hours a tablespoonful of liquor acetatis ammoniæ with five grains of carbonate of ammonia added, and had champagne, with or without soda-water, at the rate of a bottle every twenty-four hours. I may mention that this treatment and the washing out the vagina and uterus were continued throughout.

Next day, the skin was completely covered with the eruption, the tongue taking on the typical strawberry appearance, and the fauces being very much inflamed and painful. The pulse remained about 120, and the temperature ranged from $101 \mathrm{deg}$. to $104 \mathrm{deg}$.

Altogether, the case was one of pure unmixed scarlatina. I say pure, for from first to last there was not a single local puerperal symptom. On the third and fourth nights of the fever, there were some delirium and restlessness, but not more than one sees in even moderately mild cases of scarlatina. The case went on well ; desquamation began on the eighth day, and was completed before the end of a month. The patient sat up in a chair in a fortnight from her delivery, and was outof-doors in a month.

Now here is a case in which a sharp attack of undoubted scarlatina, setting in thirty-two hours after delivery, does not modify in any way the puerperal condition. There never was the slightest abdominal tenderness, or tympanites, or suppression of the lochial discharge ; the single exception being that no milk was secreted. I may mention that there was a slight laceration of the perinæum, which would of course have been favourable to the development of septicæmia. This case disposes satisfactorily of the proposition that scarlatina is necessarily transformed into malignant puerperal fever when it attacks a recently delivered woman.

On the other hand, several years ago, I had a case of which I kept notes, and of which I shall give a summary. Mrs. C. D., the wife of a labourer, was easily and safely delivered of her sixth child while three of her children were suffering from scarlet fever, which was epidemic at the time, almost every house in the neighbcurhood being infected. The cases of the children were mild, and the mother had no anxiety about them, or alarm about herself, though she had never had fever. She went on well for two days; but on the third, complained of abdominal tenderness and tympanites; her pulse rose to 140 ; the lochial discharge was suppressed; the strength rapidly sank; and, on the sixth day from her delivery, the patient died of what might well be called puerperal fever. When the case first went wrong, I looked most carefully for some specific symptom of scarlatina, but could find none; and from day to day, and several times a day, I examined the skin, throat, and tongue, but not a single feature of scarlatina could I detect. I had examined and washed out the uterus and vagina at first, and afterwards, but found nothing to account for the local mischief.

Of course, one cannot say a great deal from a case like this ; but it is my decided opinion that this, too, was a case of scarlatina, though there were no visible symptoms of it. I think the explanation is not very difficult. There can be no doubt that scarlatina does in most cases give rise to a set of symptoms and produce effects which are identical with those seen in puerperal fever ; and the very intensity of this condition is sufficient to swamp the special features of the scarlatina itself, which would otherwise be visible. This is more especially the case when the patient dies early. This production of local symptoms is not to be wondered at when the extreme susceptibility of the recently emptied uterus to any poison, whether communicated by the blood or otherwise, is considered. A case of scarlatina may te so slight of itself as to elude detection. We have all seen cases where a member of a family, some of which have suffered, or are suffering, from fever, is not very well, but we cannot pronounce his to be a case of scarlatina till we find that he afterwards desquamates. Cases like these, occurring in the puerperal condition, might easily produce fatal results and their real nature escape detection.

In connection with this, I may mention one which has a certain bearing on the subject. A little girl, of a particularly healthy constitution, slightly nipped the fleshy part of her arm in shutting a door, and beyond a little pain at the moment suffered no injury. Two days afterwards, she was taken ill of a very mild attack of scarlatina. On the second day of the fever, the arm, which was considered quite well, became very much inflamed, and a large abscess rapidly formed. The little patient suffered severely from this, both locally and constitutionally, but I may say not at all from the fever. If $I$ had not been in attendance on another member of the family suffering from fever at the time, I should probably not have been asked to see the patient till the arm was inflamed; and it is probable I might have overlooked the scarlatina, and put the whole down to the injury of the arm.

I think there can be no doubt that in some cases of puerperal scar latina, the specific symptoms of the disease may be so suppressed as to escape notice, even on careful examination; but these on that ac- count are not to be classed as malignant puerperal fever. It would be interesting and go a great way to clear up this matter, if some one who has large opportunities would bring forward some cases-if such there be-where women who have, within, say, a few years, had undoubted scarlatina have had malignant puerperal fever conveyed to them by scarlatinal infection. For my part, I should have no fear of so conveying it, any more than I should of conveying scarlatina to a non. puerperal patient from one suffering from malignant puerperal fever.

\section{CASE OF ATROPINE-POISONING.}

By A. S. GREENWAY, M.B., Assistant Medical Officer, Fulham Hospital.

Charles S., aged 45, a gardener, was brought to me about I.25 P.M. on August 6th, 1878, said to have swallowed at least a teaspoonful of liquor atropiæ sulphatis $(B . P$.$) He told me that he was attending an$ ophthalmic hospital for an affection of the eye, and received some drops and a larger bottle for internal use. He was in the habit of pouring out his daily allowance of the latter into an ounce-and-a-half phial, and carrying it in the same pocket with the atropine-bottle. About I P.M. (dinner-time), he left work, and, when he took his medicine, by mistake he drank from the wrong bottle, although the atropine-bottle was fluted, etc. - in fact, a regular poison-bottle. He felt nothing particular, but told the clerk who brought him home what he had done. He was then quite sensible; there were no symptoms or signs whatever except excessive nervousness. The left pupil was dilated from a previous application of the atropine. I gave him an emetic of ipecacuanha wine; and, it not acting quickly enough, I gave twenty grains of sulphate of zinc in mustard and water, and told him to walk about. At I.39 P.M., his pulse was 140, small and regular ; temperature 98 deg. He staggered as he walked, and complained of giddiness. The pupils were not affected. No sickness supervening, I used the stomach-pump and washed out the stomach. He lost power over his legs, and became quite helpless and unconscious; his pulse became excessively weak and irregular; and I gave him a drachm of tincture of digitalis in some brandy. At 2.15, he commenced to talk quickly, and looked flushed. At 2.45, the pulse was 148, full; and the skin dry. The face was very much flushed. He had very violent delirium, requiring three men to hold him. The pupils had gradually enlarged till they were nearly fully dilated. The tongue was dry and brown; he could swallow after some compulsion. Vomiting continued at intervals, and black coffee was given him now and then. His feet became cold; mustard was applied to them. At 3.15 P-M., the pulse was I 56, smaller; temperature $99 \mathrm{deg}$. He was quieter, and had a tendency to sleep. The pupils were the same, and insensible to light. He did not retract his legs when they were pricked or pinched. When spoken to, he did not seem to hear, being evidently quite unconscious. At 4 P.M., the pulse was 144 . He seemed generally the same, except that, when his name was shouted in his ear, he opened his eyes and turned his head in the direction of the sound. For the first time, the respiration seemed labouring and quick, accompanied by flapping of the cheeks when he was permitted to sleep. He now moved both arms and legs at times, and twitching of some of the muscles was noticed. He had a mustard poultice over his cardiac region, and small quantities of brandy were administered. An enema of castor-oil was given. At 7 P.M., the pulse was 140 ; respirations 40 per minute. $\mathrm{He}$ was more conscious. The tongue was the same, the face less flushed, and the skin still quite dry. He was decidedly more conscious, as, when told to put out his tongue, he put it out, and said "Yes" when called. He caught at imaginary objects. On account of his precarious state, I asked Dr. Milner Fothergill to see him, which he very kindly did, and advised me to continue the line of treatment, as he was recovering.

Dr. Fothergill spoke to him, and he answered him fairly intelligibly. At 9.15 P.M., the pulse was 140, small and regular; temperature 102 deg.; respiration was 50 , labouring. On examining cursorily the chest, I found a few moist rales about the bases. He recognised some friends who came to see him. The skin and tongue were in the same state as said in last report. As soon as he fell asleep, he commenced to talk unintelligibly. The pupils were the same. Neither bowels nor bladder had acted. At 10.35 P.M., the pulse was 140, full and regular; temperature 102.4 deg.; respirations 60 . The bowels had acted slightly. He was inclined to become violently delirious again, as Dr. Fothergill had foretold. Generally, he was in the same state as at the last report. He had been having eggs, coffee, milk, etc., with a little brandy at intervals. At II.45, I passed the catheter; but the bladder was empty, and there was no dulness over the pubes. $\mathrm{He}$ had considerable tympanites, and tenderness over the abdomen. 
August 7 th, I.30 A.M. The pulse was 132, full and regular; temperature 103 deg.; respirations 56 . He passed a fair quantity of urine in the sheets. His skin, pupils, and tongue were in the same state; and he complained of great thirst. He had some ice. At 2.45 , the pulse was 130, full and regular; temperature $102.6 \mathrm{deg}$; respirations 48. He was now nearly conscious and intelligible in his answers, but directly he fell asleep he commenced to talk and mutter. At 4.30 , the pulse was 92, small, and slightly irregular. He now remembered where he was, and taking the poison. He looked very pale. At 6.30, the pulse was 115 ; temperature 100.4 deg.; respirations 30 . The bowels had acted very freely three times. I ordered some ammonia and bark. At II.45, the pulse was 140, full and regular; temperature 102.2 deg.; respirations 36 . He complained of soreness at the pit of the stomach. The bowels acted twice again. He had perspired for the first time. The tongue and mouth were less dry. On applying the light of a candle to the pupils, the right contracted slightly; the left did not. He said he had very pleasant dreams. At 9 P.M., the pulse was 144, full; temperature 102.4 deg.; respirations 52. The skin was now moist. The tongue was again dry and brown. $\mathrm{He}$ felt very hot and thirsty. He pasied some urine, which, on examination, was high-coloured, turbid, of an amber colour; chlorides were present; there was no albumen; specific gravity Ior 5. At I0.40 P. M., the pulse was 156 , small; temperature $100.6 \mathrm{deg}$; respirations 52 . The pupils were still much dilated, and he complained of no pain anywhere.

August 8th, Io A.M. The night report was that he had passed a fair night, sleeping at intervals. He vomited once, and took his fcod well. The bowels acted four times. He complained to me, on my visit, of some pain over the right side of his chest, and had com. menced to cough and expectorate. He was very thirsty. The tongue was the same. The left pupil was still dilated; the right much smaller, and contracted on looking at a bright light. On examining the chest in front, both lungs were resonant and otherwise normal. Behind, at the base of the left lung, a limited area of crepitation was found, but no dulness. Over the right base, got small crepitation extending upwards to the spine of the scapula, and very slight dulness. The sputum was rust-coloured and scanty. He was ordered a mustard poultice to the right base, and three grains of carbonate of ammonia in decoction of senega every three hours; also two drachms of brandy every hour, with milk, beef-tea, etc.

August 9th, Io A.M. Pulse 160, regular; temperature 100.2 deg.; respirations 60 . He slept fairly well during the night; but this morning he again complained of pain in the right side of the chest. On examining the chest, I found absolute dulness as far as the spine of the scapula on the right side behind, as well as tubular breathing and bronchophony, but no crepitation. Over the left lung posteriorly, there was rough breathing; but otherwise the breath-sounds were healthy. I had to leave, and my colleague Mr. Cole kindly took charge of the case until he died, at 2.40 A. M. on August roth. A sudden change for the worse had set in about II P.M. of the night previous, and the symptoms increased until his death.

NECROPSY, at 7 P.M., August 12th. - The body was well nourished, there being no emaciation. He had slight talipes varus of the right foot. The abdomen was swollen, tympanitic, and had a green discoloration. The right side of the chest was duller than the left. There was very little hypostatic congestion. The pupils were slightly dilated, and there was an absence of rigidity over the whole body. The pericardium contained no fluid. The heart was enlarged and very soft. The right side was much distended with dark coagulated blood, extending into the venæ cavæ. The mitral valve admitted three fingers. The pulmonary valves were competent and healthy. The aorta was slightly incompetent and atheromatous. The left side of the heart, both auricle and ventricle, was empty, and the muscular walls soft. There were strong and extensive pleural adhesions at the apex of the right lung. After its removal, I found several small cavities filled with a chalky material, surrounded by a fibrous capsule, in the upper lobe of the right lung. The middle lobe was healthy and crepitant throughout. The lower lobe was "hepatised", non-crepitant, solid, and pieces cut from it sank in water; there was slight exudation of blood-stained material on section. There was no pleuritic effusion or adhesion at the base. The left lung had pleuritic adhesions at the apex, not so strong. On the removal of the lung, I found cicatrices existing in the apex of the lung. The rest was healthy, except some slight hypostatic congestion at the posterior edges. The liver was natural in size, but fatty on section, extremely soft, and palish in colour. The spleen was about five inches long, very soft, and friable. The kidneys were also very soft, breaking down on removal. The cortex was congested, and the capsules very adherent. The bladder contained a small quantity of urine. The csophagus had a patch of congestion at the upper extremity, and at the cardiac end some congestion extending into the cardiae end of the stomacb, which was also congested as far as its middle. The duodenum was congested at various points. At the lower end of the ileum, there was a patch of redness of the size of the palm of the hand. No breach of surface existed. The pia mater was excessively congested. The brain, on section, appeared to have more bloody points than usual; and the lateral ventricles contained some bloody serum. The substance of the brain was very soft.

\section{CLINICAL MEMORANDA.}

\section{AMPUTATION OF ARM FOR COMPOUND COMMI- NUTED FRACTURE : LABOUR TEN HOURS AFTER OPERATION : RECOVERY.}

THE following brief report presents a complication in the aftermanagement of amputations which is not of frequent occurrence, and appears to me to be worthy of record.

A woman aged 35 was admitted into Magherafelt Union Hospital in November 1876, in an extreme state of collapse and quite delirious, having had her left arm "shattered" up to above the elbow-joint in the rollers of a flax-mill about eleven miles distant from town. She had evidently lost blood in considerable quantity ; and on examination was found to be far advanced in pregnancy; but this she totally denied. Reaction having set in next morning, the limb was removed at the middle third by the ordinary circular operation. Chloroform was not given. A flannel-and-calico bandage was used as a substitute for Esmarch's bandage, which answered the purpose remarkably well. It was of importance in this case that as little blood shculd be lost as possible. After the patient was removed to bed, an opiate was given; but it was remarked by the nurse that soon after the operation she became extremely restless and excited, but never gave any other indication of being in labour. At my evening visit, she said she was doing well, and did not complain of pain; and her pulse was quiet. Two hours after I lefr, she insisted upon getting out of bed, but was restrained from doing so. It was then evident that she was in labour, and could not conceal the fact any longer; and at about 9.30 P.M. (ten hours after operation) she was delivered of a son, the patient lying on her back. The placenta came away soon afterwards. There was no hæmorrhage from the stump.

It is unnecessary to give a daily account of the case; suffice it to say, she made an uninternupted recovery, and suckled her child. I may add that she has since told me that labour commenced immediately after the operation, and she was consequently ten hours ill. She also stated she was about two or three weeks from the full period of being delivered. Both mother and child left the hospital healthy and well, but I understand the child has since died of croup.

Agmon B. Vesey, Medical Officer to Magherafelt Union Workhouse and Fever Hospital, Consulting Sanitary Officer, etc., County Derry.

MENINGEAL APOPLEXY : RECOVERY.

J. B., AGED 60, married and with a grown-up family, had always been an extremely temperate man and healthy, with the exception of chronic rheumatism, which had somewhat crippled him. He had no history of fits or injuries to the head, etc. Both his parents were dead, there being no special history connected with either. He himself had lately had some domestic trouble. On Saturday, he was at work as usual, and on Sunday morning felt as well as ever, nothing remarkable being noticed in his manner. On Sunday afternoon, he seemed irritable and complained of pain in the head. Later on, he went out and returned with a brush in his hand, and, on being asked why he had done so, replied that he "was going to sweep away his sorrows". He also placed a cushion on his head, thinking it was a hat. His speech was "confused".

About 8.30 on Sunday evening, I was sent for; and, on reaching his house (some miles in the country), I found him standing by a chair, against which he was supporting himself. He was in a half-dressed state; face slightly flushed; manner restless and excited. He was constantly dressing and undressing himself. The pupils were natural and equal, but the eyes were very sensitive to light. On being spoken to or touched, he spoke in an angry tone, and seemed to be much irritated. Temperature, pulse, and respiration could not be taken. No paralysis was detected. The people in the room were afraid to go near him. I could not understand what he said. $\mathrm{He}^{\circ}$ was not sensible of any surrounding object, except when touched. Urine was copious and 